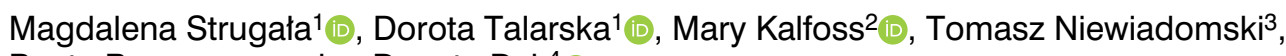 \\ Beata Rozmarynowska, Danuta Dyk ${ }^{4}$ (D) \\ ${ }^{1}$ Department of Preventive Medicine, University of Medical Sciences, Poznan, Poland \\ 2Diakonova University College, Oslo, Norway \\ ${ }^{3}$ Orthopaedics-Rehabilitation Clinical Hospital, University of Medical Sciences, Poznan, Poland \\ ${ }^{4}$ Department of Nursing Anaesthesiology and Intensive Care, University of Medical Sciences, Poznan, Poland
}

\title{
Perception of illness by patients treated with haemodialysis
}

\author{
Corresponding author: \\ Magdalena Strugała, \\ Department of Preventive Medicine, \\ University of Medical Sciences, \\ Święcickiego 6 Str., \\ 60-781 Poznan, Poland, \\ e-mail: magdastrugal@ump.edu.pl
}

Medical Research Journal 2019; Volume 4, Number 4, 193-200 10.5603/MRJ.a2019.0035 Copyright (C) 2019 Via Medica ISSN 2451-2591

\begin{abstract}
Introduction: Perception of illness is the way in which a condition is perceived, which reflects the patient's attitude towards illness and treatment.

Aim: The aim of the research was to understand the perception of illness among patients treated with haemodialysis. The specific goal was to determine the factors affecting the perception of the illness and their interrelationships.

Material and methods: The study included 98 people treated with haemodialysis as part of the international project "Health, coping, and quality of life in people with chronic kidney disease and in their families". As research tools the following were used: the Barthel Index, Instrumental Activities of Daily Living Scale (IADL), Edmonton Symptom Assessment Scale - Revised (ESAS - R), and the Brief IIIness Perception Questionnaire (Brief IPQ) Scoring Instructions.

Results: The perception of illness in the study group was significantly influenced by the intensity of physical symptoms ( $p=0.007$ ), especially dyspnoea or fatigue. Whereas, the following areas of the perception of illness: Consequences, Treatment control, Timeline, Illness concern, and Comprehensibility were mainly affected by functional efficiency, age, and education level. A worse perception of illness was observed with the increase in IADL dependency, younger age, and lower education level.

Conclusions:

1. Perception of illness in the study group was at a moderate level.

2. Perception of illness in the study group was most strongly influenced by the intensity of symptoms, especially dyspnoea and fatigue.

3. Functional efficiency, age, and education significantly affected the perception of illness.

Key words: perception of illness, haemodialysis
\end{abstract}

Med Res J 2019; 4 (4): 193-200

\section{Introduction}

The perception of illness by patients with end-stage renal disease (ESRD) is not a topic often addressed in the literature. Researchers mainly focus on various aspects of treatment, transplantation, biochemical test results, etc. while little attention is paid to the struggles of patients in their everyday functioning [1]. Understanding the perception of illness among patients with ESRD facilitates and strengthens the effects of therapy and care [2].

The perception of illness is defined as the "emotional and cognitive representation of the disease". It contains beliefs about the aetiology of the illness, its symptoms, subjective personal consequences of the illness, and the degree to which the illness can be controlled or treated [3]. It also means that patients create certain mental models of their illness in order to interpret body experiences, reduce symptoms and psychological suffering, and also to seek to understand the illness and the role of its impact on their life [4]. An individual's perception of illness also impacts functional adjustment to disability and affects the way a patient follows recommendations related to the disease $[3,5]$.

In chronic illnesses, such as ESRD, the severity of symptoms as well as the duration and nature of treatment significantly impact patient quality of life [6]. Patients with ESRD experience the impact of many 
interconnected stressors. Work and finances are disrupted, as are family and personal relations, recreation, and general health. There are various symptoms, such as chronic pain, dyspnoea, fatigue, and lowered mood (disease intolerance). It is important to identify the symptoms that are the main cause of psycho-physical discomfort among dialysis patients because they affect the patient's general well-being. They can influence the particular perception of illness, and they are not always part of routine clinical evaluations [7, 8, 9]. More severe symptoms are usually reported by patients who are worried about the course of their illness and experience unpleasant emotions (such as sadness or anger). The form of the treatment, haemodialysis, determines the time of activities undertaken during the day by the patient and is a significant economic burden. Some patients do not adapt well to the treatment procedures and manage their time poorly. This limits their independence and reduces self-esteem and self-confidence. They are more likely to say that the disease significantly affects their lives [10].

Maintaining fitness and independence is essential, not only for general patient well-being and effectiveness of therapy but also as a factor that significantly reduces the number of complications, recurrent hospitalisation, and even mortality for haemodialysed patients [11, 12]. People treated with haemodialysis are characterised by a varied degree of functional capacity when compared with the general population [13]. Currently, both in retrospective and prospective studies [14, 15], increased levels of functional activity in patients with ESRD can be found. Undoubtedly, this is a result of medical advances, including technological solutions that influence the general quality of life and foster improved functioning. Although patients with ESRD do no not usually experience major difficulties in everyday functioning, the most common problems for them are inability to work and disturbed family relations. The intensity of symptoms, functional fitness, and applied therapy have a significant influence on the perception of illness, including ESRD [8].

\section{Aim}

The aim of this study was to understand the way that illness is perceived by patients treated with haemodialysis. The specific aim was to determine factors affecting the perception of illness and their interrelationships.

\section{Material and methods}

As part of the international project "Health, coping, and quality of life in people with chronic kidney disease and in their families", a group of 98 people treated with haemodialysis in two renal replacement therapy centres in the city of Poznan, Poland were studied.

\section{Organisation of the study}

Permission was obtained to conduct research in two of the four haemodialysis centres in the city of Poznan. Each patient was informed in detail about the aim of the study, and the research instruments were discussed. Ultimately, 105 people participated in the study because seven questionnaires were rejected during the study due to not being filled out or patient withdrawal.

The conditions for participation in the study were patient consent, a psychosocial condition enabling independent completion of the questionnaire, and the absence of other debilitating illnesses.

\section{Research instruments}

The Barthel Index of Activities of Daily Living - a scale of 0 to 100 points. Patients with score above 86 are in good functional condition, while a score below 20 indicates severe impairment.

The Instrumental Activities of Daily Living (IADL) Scale - the version with nine questions, with three options for answers was used: 1 point indicates full dependence, 2 points - partial dependence, and 3 - independence. The maximum total score is 27 points.

The Edmonton Symptom Assessment Scale - Revised (ESAS - R) - the scale contains 10 questions about the degree of perceived symptoms that may accompany haemodialysis: pain, fatigue, somnolence, nausea, appetite, dyspnoea, depression, nervousness, well-being, and other problems (e.g. constipation). The response range is within the range 0 pts (no symptoms) to 10 pts (maximum intensity). Each symptom is analysed separately.

The Brief IIIness Perception Questionnaire (Brief IPQ) - this is a questionnaire that provides a quick assessment of the perception of illness (Weinman et al.). It consists of nine questions about the perception of and attitudes towards illness. The rating for questions $1-8$ is based on a Likert scale, ranging from 0 to 10 points. During the analysis in questions 3, 4, and 7 answers must be reversed. Questions 1 to 5 determine the cognitive perception of illness, 6 and 8 the emotional perception, while question 7 is about understanding the illness. Question 9 is open, allowing respondents to give reasons they recognise for the disease to occur. The higher the score on the scale, the more harmful the effect of the illness.

Individual questions are analysed separately, but if the study requires it, then a sum (0-80 pts) can be taken into account that reflects the degree to which the disease is perceived negatively. The higher the point total the more negative the perception of illness [5]. 
Questions on the Brief IPQ scale have been adapted into three areas:

\begin{tabular}{|c|c|}
\hline $\begin{array}{l}\text { 1. cognitive representation } \\
\text { of illnesses perception: }\end{array}$ & $\begin{array}{l}\text { 2. emotional } \\
\text { representation: }\end{array}$ \\
\hline Brief - IPQ 1-consequences & Brief - IPQ 6-concern \\
\hline Brief - IPQ 2 - timeline & Brief - IPQ 8 - emotions \\
\hline $\begin{array}{l}\text { Brief - IPQ 3 - personal } \\
\text { control }\end{array}$ & 3. comprehensibility: \\
\hline $\begin{array}{l}\text { Brief - IPQ 4-treatment } \\
\text { control }\end{array}$ & $\begin{array}{l}\text { Brief - IPQ 7- } \\
\text { comprehensibility }\end{array}$ \\
\hline \multirow[t]{2}{*}{ Brief - IPQ 5 - identity } & $\begin{array}{l}\text { Brief - IPQ 9-the causes } \\
\text { of disease }\end{array}$ \\
\hline & Brief-IPQ - score \\
\hline
\end{tabular}

\section{Statistical analysis}

Analysis was performed using the STATISTICA 10 PL package (StatSoft Inc.). Differences between two independent groups were evaluated using the non-parametric Mann-Whitney test and the parametric Student's t-test. Correlations were assessed using Spearman's $r_{s}$ rank correlation coefficient. Nominal variables were analysed using Pearson's chi-squared test. To identify factors significantly affecting the risk of falls, a logistic regression model was used. Results obtained were presented as odds ratios with $95 \%$ confidence intervals. A two-factor ANOVA AB variance analysis and Levene Test were used for variance error homogeneity. All the tests were considered statistically significant at $p<0.05$.

\section{Variable analysis}

Age was analysed in two groups: up to 60 years and over 60 years. Taking into account the average duration of dialysis, two groups were distinguished: up to 48 months and over 48 months. Marital status was analysed in two groups: married and unmarried.

\section{Results}

\section{Demographic and clinical data}

The study included 61 (62.24\%) men and 37 (37.76\%) women, aged $18-85$ years. The mean age was $59.65 \pm 15.51$ years. Married persons dominated $(n=67,68.37 \%)$. Half of the group were retirees $(50.00 \%)$; the next most numerous group were those on disability (35.71\%). Only six (6.12\%) persons worked professionally. The mean haemodialysis time for the entire group was $42.67 \pm 50.30$ months (Tab. 1). The most common reasons for dialysis were chronic glomerular nephritis (21.43\%), diabetic nephropathy (18.37\%), polycystic kidney disease (12.24\%), and hypertensive nephropathy $(9.18 \%)$.

\section{Functional status of the subjects}

Patients included in the study showed a fairly large degree of independence in undertaking basic and instrumental activities (Tab. 2). In the Barthel Index $64(65.31 \%)$ patients obtained scores indicating low impairment, while the scores of 34 (34.69\%) patients indicated moderately severe impairment.

People aged under $\mathbf{6 0}$ years were more efficient in basic (ADL) and instrumental (IADL) life activities (Student's t-test: Barthel $[p<0.000]$ and IADL $[p<0.001])$.

There were no differences between the time of dialysis (Student's t-test) and the efficiency of patients

Table 1. Demographic factors

\begin{tabular}{|c|c|c|c|c|c|c|}
\hline Demographic variables & $\begin{array}{l}\text { Women } \\
\mathrm{n}=53\end{array}$ & $(53 \%)$ & $\begin{array}{l}\text { Men } \\
n=47\end{array}$ & $(47 \%)$ & $\begin{array}{l}\text { All } \\
n=100\end{array}$ & $(100 \%)$ \\
\hline \multicolumn{7}{|l|}{ Age } \\
\hline $20-40$ years & 7 & $13.2 \%$ & 4 & $8.5 \%$ & 11 & $11 \%$ \\
\hline $41-65$ years & 25 & $47.2 \%$ & 27 & $57.4 \%$ & 52 & $52 \%$ \\
\hline $66-90$ years & 21 & $39.6 \%$ & 16 & $34.1 \%$ & 37 & $37 \%$ \\
\hline \multicolumn{7}{|l|}{ Educational level } \\
\hline elementary & 19 & $35.8 \%$ & 12 & $25.5 \%$ & 31 & $31 \%$ \\
\hline vocational & 19 & $35.8 \%$ & 23 & $48.9 \%$ & 42 & $42 \%$ \\
\hline secondary & 12 & $22.7 \%$ & 8 & $17.0 \%$ & 20 & $20 \%$ \\
\hline post-secondary & 3 & $5.7 \%$ & 4 & $8.5 \%$ & 7 & $7 \%$ \\
\hline \multicolumn{7}{|l|}{ Marital status } \\
\hline single & 9 & $17.0 \%$ & 8 & $17,0 \%$ & 17 & $17 \%$ \\
\hline married & 26 & $49.0 \%$ & 33 & $70.2 \%$ & 59 & $59 \%$ \\
\hline divorced & 3 & $5.7 \%$ & 2 & $4.3 \%$ & 5 & $5 \%$ \\
\hline widowed & 15 & $28.3 \%$ & 4 & $8.5 \%$ & 19 & $19 \%$ \\
\hline
\end{tabular}


Table 2. Evaluations from the Health Questionnaire Specific for End-Stage Renal Disease with respect to demographic variables

\begin{tabular}{|c|c|c|c|c|c|c|c|c|}
\hline \multirow{3}{*}{$\begin{array}{l}\text { Indexes } \\
\text { Objective QOL } \\
\text { (0-10 pts.) }\end{array}$} & \multicolumn{8}{|c|}{ Variables } \\
\hline & \multicolumn{2}{|l|}{ Age* } & \multicolumn{2}{|l|}{ Sex* } & \multicolumn{2}{|c|}{ Educational level* } & \multicolumn{2}{|c|}{ Marital status* } \\
\hline & $\begin{array}{c}<60 \\
5.7 \pm 1.5 \\
>60 \\
4.5 \pm 1.5\end{array}$ & $<0.001$ & $\begin{array}{c}F 4.6 \pm 1.4 \\
M \\
5.6 \pm 1.8\end{array}$ & 0.006 & $\begin{array}{c}B \\
4.8 \pm 1.6 \\
H 5.8 \pm 1.6\end{array}$ & 0.009 & $\begin{array}{c}\text { S } 4.5 \pm 1.4 \\
M \\
5.4 \pm 1.7\end{array}$ & 0.006 \\
\hline $\begin{array}{l}\text { Subjective QOL } \\
\text { (0-100 pts.) }\end{array}$ & $\begin{array}{l}<6063.5 \pm 12.5 \\
>6052.1 \pm 13.3\end{array}$ & $<0.001$ & $\begin{array}{l}\text { F } 54.3 \pm 14.1 \\
\text { M } 61.1 \pm 13.4\end{array}$ & 0.014 & $\begin{array}{l}\text { В } 54.7 \pm 13.8 \\
\text { H } 64.8 \pm 12.4\end{array}$ & 0.003 & $\begin{array}{l}\text { S } 55.1 \pm 14.4 \\
M 59.2 \pm 13.7\end{array}$ & 0.105 \\
\hline $\begin{array}{l}\text { Physical symptom } \\
\text { scale } \\
\text { (12-60 pts.) }\end{array}$ & $\begin{array}{c}<60 \\
46.7 \pm 5.1 \\
>60 \\
43.7 \pm 5.9\end{array}$ & 0.005 & $\begin{array}{l}F 43.6 \pm 5.6 \\
M 46.8 \pm 5.4\end{array}$ & 0.004 & $\begin{array}{l}\text { В } 44.5 \pm 5.9 \\
\text { Н } 46.9 \pm 5.1\end{array}$ & 0.084 & $\begin{array}{l}S 43.9 \pm 6.0 \\
M 46.0 \pm 5.5\end{array}$ & 0.105 \\
\hline $\begin{array}{l}\text { Affect scale } \\
\text { (12-60 pts.) }\end{array}$ & $\begin{array}{c}<60 \\
41.5 \pm 9.7 \\
>60 \\
38.7 \pm 6.4\end{array}$ & 0.096 & $\begin{array}{l}F 37.8 \pm 5.4 \\
M 42.6 \pm 9.9\end{array}$ & 0.002 & $\begin{array}{l}\text { B } 38.8 \pm 5.9 \\
H 43.4 \pm 12.0\end{array}$ & 0.029 & $\begin{array}{l}S 37.1 \pm 6.0 \\
M 42.1 \pm 8.9\end{array}$ & $<0.001$ \\
\hline $\begin{array}{l}\text { Satisfaction with life } \\
\text { scale } \\
\text { (1-7 pts.) }\end{array}$ & $\begin{array}{c}<60 \\
4.6 \pm 0.9 \\
>60 \\
3.7 \pm 1.0\end{array}$ & 0.000 & $\begin{array}{c}\mathrm{F} \\
3.8 \pm 1.0 \\
\mathrm{M} 4.4 \pm 0.9\end{array}$ & 0.004 & $\begin{array}{c}B \\
4.0 \pm 1.0 \\
H 4.4 \pm 1.0\end{array}$ & 0.051 & $\begin{array}{c}S 3.8 \pm 1.0 \\
M \\
4.3 \pm 0.9\end{array}$ & 0.018 \\
\hline $\begin{array}{l}\text { General affect } \\
\text { (1-7 pts.) }\end{array}$ & $\begin{array}{c}<60 \\
4.5 \pm 0.9 \\
>60 \\
3.8 \pm 0.9\end{array}$ & $<0.001$ & $\begin{array}{l}\mathrm{F} 4.0 \pm 1.0 \\
\mathrm{M} 4.4 \pm 0.9\end{array}$ & 0.012 & $\begin{array}{l}\text { B } 3.9 \pm 0.9 \\
H 4.7 \pm 0.9\end{array}$ & 0.000 & $\begin{array}{c}\text { S } 3.7 \pm 1.0 \\
M \\
4.4 \pm 0.9\end{array}$ & $<0.000$ \\
\hline $\begin{array}{l}\text { Well-being } \\
(2.1-14.7 \text { pts.) }\end{array}$ & $\begin{array}{c}<60 \\
9.5 \pm 1.7 \\
>60 \\
7.9 \pm 1.9\end{array}$ & $<0.001$ & $\begin{array}{c}F \\
8.2 \pm 2.0 \\
M 9.3 \pm 1.7\end{array}$ & 0.004 & $\begin{array}{c}B \\
8.3 \pm 1.9 \\
H 9.6 \pm 1.9\end{array}$ & 0.005 & $\begin{array}{c}S \\
7.9 \pm 2.0 \\
M 9.2 \pm 1.8\end{array}$ & $<0.000$ \\
\hline
\end{tabular}

*Test Mann-Whitney, statistically significant $p$-value $p<0.05$.

Key: age: < 60 below $60,>60$ above 60 ; sex: $\mathrm{F}$ - female, $\mathrm{M}$ - male; education: $\mathrm{B}$ - basic (elementary, vocational), $\mathrm{H}$ - secondary and postsecondary); marital status: $\mathrm{S}$ - single, $\mathrm{M}$ - married

for ADL ( $p>0.05)$ and IADL ( $p>0.05)$. There was no difference in functional status in the study group when marital status $(p>0.05)$ and duration of dialysis therapy $(p>0.05)$ were taken into account. A mong women, those under 60 years of age and those with a higher level of education had a higher level of functional efficiency (ADL and IADL).

\section{Severity of ESAS-R symptoms}

On the ESAS-R symptom severity scale the mean score in the study group was $16.72 \pm 14.09$ out of 100 possible points, which means that most of the patients' symptoms occurred at a low level of intensity. Out of 10 analysed symptoms, the most severe (7-10 pts) was fatigue and drowsiness, which occurred at a significant intensity in $18.37 \%$ of those surveyed. The least severe (0-4 pts) were nausea $(92.86 \%)$, depression (84.69\%), dyspnoea (83.67\%), and other problems such as constipation (76.53\%). The mean score on the entire scale for women was $17.41 \pm 13.92$ and for men $16.31 \pm 14.30$. Women most often reported feeling unwell $(54.10 \%$; $62.16 \%)$ while men reported fatigue (65.57\%; 59.46\%) and drowsiness (63.93, 59.46\%). When the sex of the patients is considered, only a difference between the feeling of discomfort and loss of appetite was found (Student's t-test 42.97; $\mathrm{p}<0.05$ ); more often this disorder occurred in women (M 24.59\%; $\mathrm{W} 32.43 \%)$. Patients aged under 60 years scored $15.80 \pm 12.56$ points, while for those over 60 years of age the score was $17.69 \pm 15.61$ points. The age of respondents correlated with the feeling of pain (Spearman's test $\left.r_{s} p<0.008\right)$, loss of appetite $(p<0.046)$, and other occurring problems $(p<0.002)$. There was no correlation between education and severity of symptoms. The duration of renal replacement therapy correlated (test $r_{s}$ ) with loss of appetite $(p<0.0322)$, dyspnoea ( $p<0.0479)$, and nervousness ( $p<0.0115)$. A greater severity of symptoms affected patients aged over 60 years. 


\section{Brief IPQ}

The perception of illness in the study group was at a moderate level. Scoring was in the middle of the scale and was $46.68 \pm 8.80$ points (Tab. 3 ). The highest score, i.e. the most negative responses, was found in the question about Timeline (9.21 points) and Consequences (7.36 points). A positive element was the patients' perception of the low impact of disease symptoms on their lives (Identity - 5.57 points) and worrying (Illness concern -5.65 poits).

There was no significant correlation between gender and perception of illness. The statistically significant difference (Mann-Whitney test $p=0.027$ ) was only found in the question about worrying about own illness
(How concerned are you about your illness?). Women answered this question more negatively (W 6.24; M 5.29)

Age differed perceptions of the disease in the Timeline area ( $<60$ years $8.72 ;>60$ years 9.60 Mann-Whitney test $p=0.000)$ and Emotional representation ( $<60$ years $5.93 ;>60$ years 5.05 points, $p=0.016$ ). Older people were more often convinced that the disease would last for the rest of their lives, whereas younger people more often experienced discomfort due to disease onset (Fig. 1).

The perception of illness was also different depending on education. People with lower education level more often worried about their illness and experienced it emotionally (Fig. 2).

Table 3. Correlation between sub-scales of the Health Questionnaire Specific for End-Stage Renal Disease*

\begin{tabular}{lccccccc}
\hline Sub-scales & PS & AS & IOLS & IGA & IW & SQOLS & OQOLS \\
\hline The physical symptom scale - PS & - & 0.62 & 0.63 & 0.56 & 0.61 & 0.66 & 0.63 \\
The Affect scale -AS & 0.62 & - & 0.68 & 0.66 & 0.70 & 0.63 & 0.69 \\
Index of overall life satisfaction - IOLS & 0.63 & 0.68 & - & 0.85 & 0.94 & 0.84 & 0.82 \\
Index of general affect - IGA & 0.56 & 0.66 & 0.85 & - & 0.96 & 0.79 & 0.85 \\
Index of well-being - IW & 0.61 & 0.70 & 0.94 & 0.96 & - & 0.84 & 0.87 \\
Subjective QOL scale & 0.66 & 0.63 & 0.84 & 0.79 & 0.84 & - & 0.83 \\
- SQOLS & & & & & & & \\
Objective QOL scale - OQOLS & 0.63 & 0.69 & 0.82 & 0.85 & 0.87 & 0.83 & - \\
\hline
\end{tabular}

${ }^{*} \mathrm{R}$ - Spearman correlation co-efficient, $\mathrm{p}<0.05$; PS - The physical symptom scale; AS — The affect scale; IOLS — Index of overall life satisfaction; IGA — Index of general affect; IW — Index of well-being; SQOLS - Subjective QOL Scale; OQOLS - Objective QOL Scale

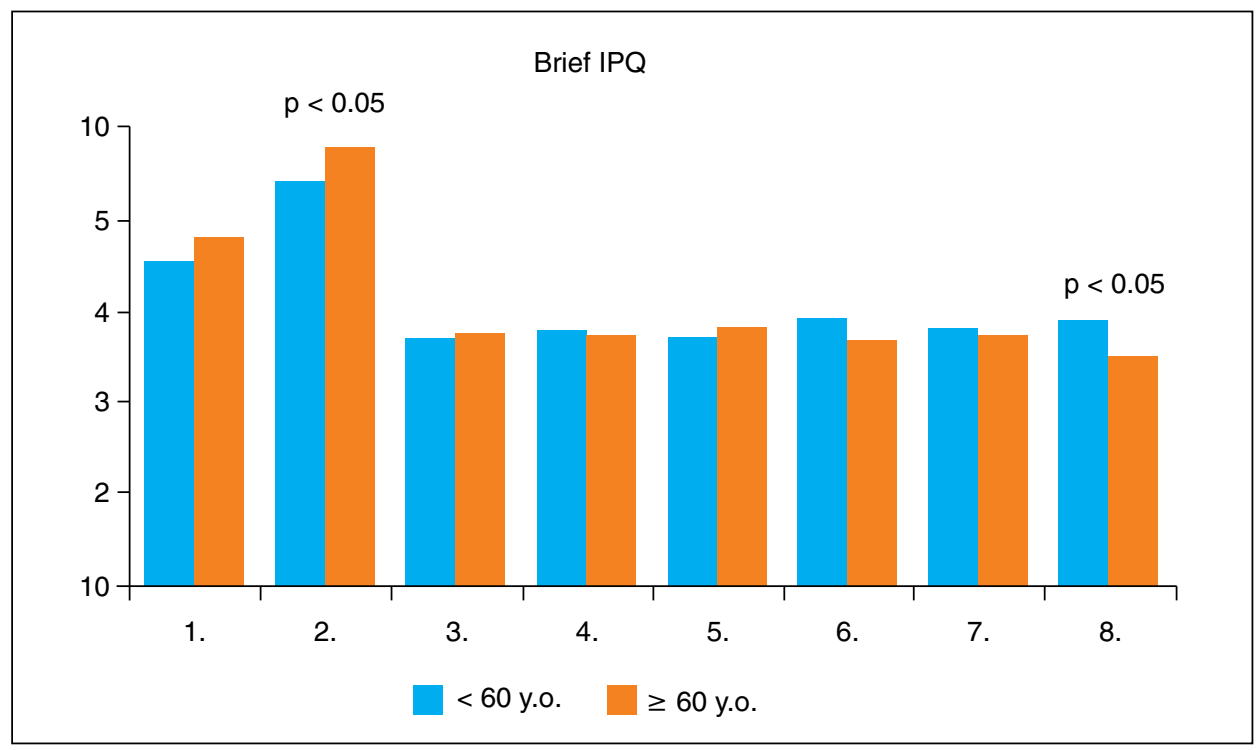

Figure 1. Age vs. Brief IPQ

1. Consequences, 2. Timeline, 3. Personal control, 4. Treatment control, 5. Identity, 6. Illness concern, 7. Comprehensibility, 8. Emotions 


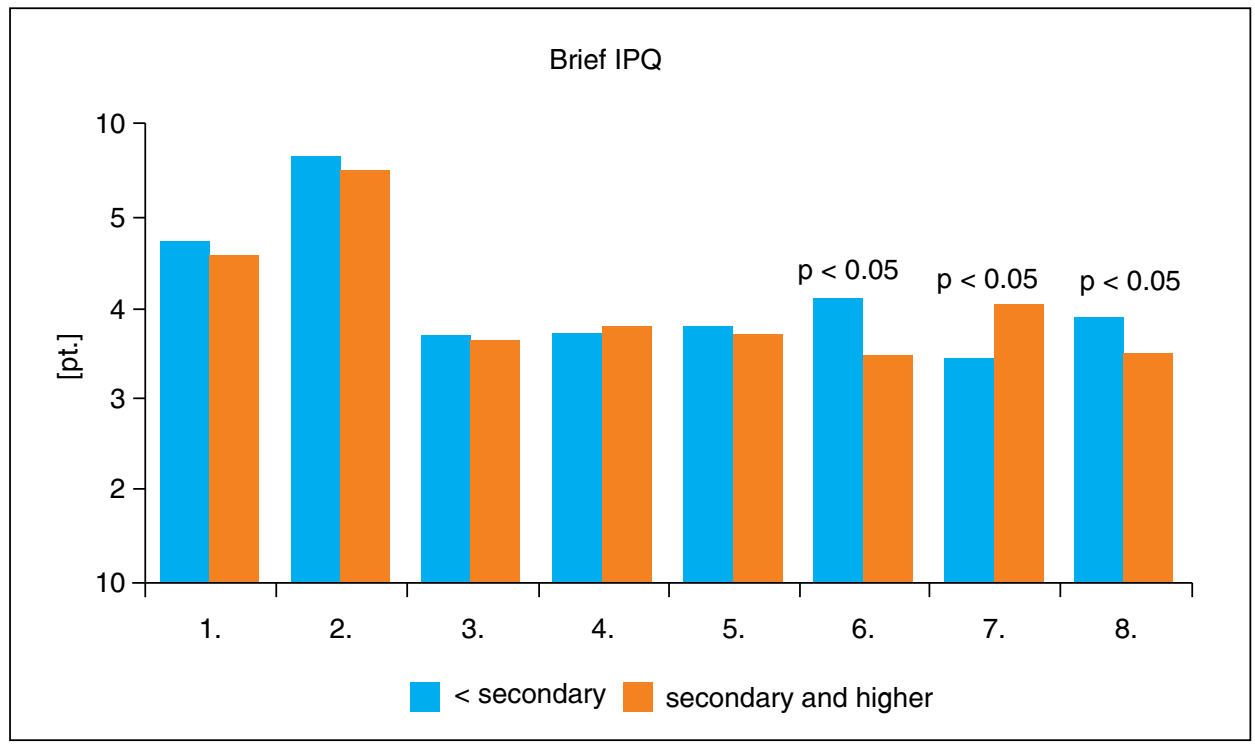

Figure 2. Education vs. Brief IPQ

1. Consequences, 2. Timeline, 3. Personal control, 4. Treatment control, 5. Identity, 6. Illness concern, 7. Comprehensibility, 8. Emotions

Analysis of the duration of dialysis showed, with the use of Pearson's linear correlation coefficient, a single correlation between area 7 -Comprehensibility $(p=0.009)$ and duration of dialysis. Taking into account the functional status a statistically significant correlation between the efficiency in IADL and the answer to questions: $1-(p=0.000), 3-(p=0.020)$, $4-(p=0.000), 5-(p=0.017)$, and $6-(p=0.020)$ was found. Worse perception of illness was observed with increasing limitations and inefficiency (IADL).

\section{Two-factor variance analysis (ANOVA AB)}

Demographic data, apart from age and education, were not variables significantly influencing the perception of illness in the study group. Hence, in further analyses an attempt was made to explain whether age in combination with other variables had an impact on the perception of illness. Differences in the perception of illness were found only when both age and marital status were taken into account ( $F$ 4.256, $p=0.017$ ). Older and unmarried people perceived the disease worse. Education was another significant variable. The perception of illness differed with sex and education taken into account in the following areas: 5 - Identity $(p=0.028), 6$ - Illness concern $(p=0.009)$, and 8 -Emotions ( $p=0.012)$. In the above-mentioned areas women with higher education level perceived the illness less negatively. Among men, education did not affect the perception of illness. In area 7 - Comprehensibility $(p=0.000)$ both women and men with higher education perceived their state of knowledge about the disease as subjectively better.

There was no significant change in the perception of illness taking into account age and sex together ( $F$ 0.368, $p=0.546)$; age and education ( $F$ 1.210, $p=0.274)$; age and time of haemodialysis ( $F 0.516$, $\mathrm{p}=0.474)$; and sex and haemodialysis time ( $\mathrm{F} 0.008$, $p=0.928)$.

\section{Brief IPQ vs. ESAS}

Of the 10 symptoms analysed, the most severe (7-10 points) were fatigue and somnolence in $18.37 \%$. The least severe (0-4 points) were nausea (92.86\%), depression (84.69\%), dyspnoea (83.67\%), and other problems such as constipation (76.53\%).

The relationship between some areas of Brief IPQ scale and particular ailments included in ESAS scale has been demonstrated (Tab. 4). Most relationships were found between area 4 and 2 and individual symptoms. Assessment of area 4 - Treatment control $(p<0.05)$ depended on the persistence of symptoms: pain, fatigue, anxiety, loss of appetite, mood, and dyspnoea. On the other hand, assessment of area 2 - Timeline was dependant $(p<0.05)$ on severity of symptoms: pain, fatigue, anxiety, mood, and dyspnoea.

One symptom that showed correlation with all areas of the Brief IPQ scale $(p<0.05)$ was dyspnoea. Another symptom with which correlation was found relatively often was fatigue (five areas). Other symptoms had different effects on the perception of illness. 
Table 4. Correlation between sub-scales of the Health Questionnaire Specific for End-Stage Renal Disease and functional status and time on haemodialysis

\begin{tabular}{lcccccccccc}
\hline $\begin{array}{l}\text { Scale/ } \\
\text { Variable }\end{array}$ & PS & AS & IOLS & IGA & IW & SQOLS & OQOLS & KPSS & BI & IADL \\
\hline KPSS & 0.72 & 0.65 & 0.76 & 0.76 & 0.79 & 0.85 & 0.81 & - & 0.81 & 0.83 \\
IB & 0.65 & 0.55 & 0.60 & 0.60 & 0.62 & 0.72 & 0.70 & 0.81 & - & 0.92 \\
IADL & 0.62 & 0.57 & 0.63 & 0.65 & 0.66 & 0.74 & 0.73 & 0.83 & 0.92 & - \\
THD & 0.04 & 0.12 & 0.07 & -0.06 & -0.01 & -0.03 & -0.01 & -0.05 & 0.03 & 0.02 \\
\hline
\end{tabular}

*Statistically important; PS - The physical symptom scale; AS — The affect scale; IOLS — Index of overall life satisfaction; IGA — Index of general affect; IW - Index of well-being; SQOLS — Subjective QOL Scale; OQOLS — Objective QOL Scale; KPSS - Karnofsky Performance Status Scale; BI — Barthel Index; IADL — IADL Lawton-Brody Scale; THD — Time on Haemodialysis

\section{Discussion}

The main area of interest of the study was to assess perception of illness with the use of the Brief IPQ tool among patients with ESRD treated with haemodialysis. The evaluation included: severity of symptoms, functional efficiency, and selected sociodemographic factors.

According to the literature, perception of illness and the development of coping strategies is conditioned by sociodemographic, medical, psychological, and behavioural factors [3, 16-18]. In this study it was shown that perception of illness in the study group was most affected by the level of severity of symptoms, especially those of dyspnoea and fatigue. Individual areas of perception of illness were influenced by functional efficiency, age, and education.

Considering the results related to the perception of illness based on the Brief IPQ tool, it was shown that the perception of illness is at a moderate level.

Other researchers report [19-21] that ESRD patients undergoing renal replacement therapy experience many physical and emotional symptoms, which were evaluated in the present study with the use of the ESAS scale. It was noticed that physical symptoms of the disease, with the exception of chronic fatigue and dyspnoea, were not significantly severe and in terms of frequency they were similar to those of other researchers [19, 21]. Low severity of symptoms was probably due to the still short period of dialysis therapy and had an impact also on better functional capacity of the subjects.

The influence of the frequency and severity of symptoms on the perception of illness was also observed by other researchers [20, 22]. The degree of this influence and attitudes towards the illness, in turn, are quite diverse. In this research physical symptoms had a greater impact on the perception of illness than in other authors' reports [23-26].

The authors of the works cited above concluded that identity and mental health are of decisive importance for the perception of illness. The quoted researchers found that a negative emotional background accompanying chronic disease, and even depressive or anxiety disorders, are more significant for the perception of illness than are physical symptoms. Our study also looked at the impact of depression, mood, and anxiety on the perception of illness, but this did not prove to be significant. It is possible that differences in the results obtained stem from the type of a study tool used by authors and/or the heterogeneity of the group. Respondents in this study differed from other groups in terms of their socio-demographic situation, the duration of the disease, and the duration of dialysis.

Following the relationship between functional capacity exponents and socio-demographic variables with the way the disease is perceived, worse perception of illness was found in those who scored as more dependent on the IADL questionnaire as well as younger and less educated respondents. Similar results were also obtained by other researchers [1, 7, 27-31]. These researchers emphasise that more functional patients with ESRD show better health, less severe symptoms, and usually have a better understanding of their illness. The manner of experiencing and subjective reception of the illness change over time and can be strongly dependent on the stage of the chronic illness [32].

To summarise the results obtained in this study, it should be emphasised that a moderate, borderline negative way of perceiving illness may result from the awareness of the chronic nature of the illness and the necessity of undergoing frequent and exhausting dialysis therapy. The positive assessment of the situation may be influenced by a shorter duration of dialysis treatment and a slight increase in the symptoms associated with it. Studies carried out by other authors have shown that in patients with end-stage renal disease undergoing haemodialysis, the perception of illness gradually worsens as the duration of the disease progresses [6, 33-35].

This research had some limitations. The results regarding functional capacity were based on information 
obtained directly from patients, i.e. they are declarative in nature. Therefore, they should be interpreted with caution.

\section{Conclusions}

\section{The perception of illness in the study group was at} a moderate level.

2. The perception of illness in the study group was most influenced by the severity of symptoms, especially dyspnoea and fatigue.

3. Functional efficiency, age, and education significantly affected the perception of illness.

\section{References:}

1. Jassal SV, Karaboyas A, Comment LA, et al. Functional Dependence and Mortality in the International Dialysis Outcomes and Practice Patterns Study (DOPPS). Am J Kidney Dis. 2016; 67(2): 283-292, doi: 10.1053/j.ajkd.2015.09.024, indexed in Pubmed: 26612280

2. Ramondt S, Tiemensma J, Cameron LD, et al. Drawings of Blood Cells Reveal People's Perception of Their Blood Disorder: A Pilot Study. PLoS One. 2016; 11(4): e0154348, doi: 10.1371/journal.pone.0154348, indexed in Pubmed: 27123580.

3. Moss-Morris R, Weinman J, Petrie K, et al. The Revised IIIness Perception Questionnaire (IPQ-R). Psychology \& Health. 2002; 17(1): 1-16, doi: 10.1080/08870440290001494.

4. Petrie KJ, Weinman J. Why illness perceptions matter. Clin Med (Lond) 2006; 6(6): 536-539, doi: 10.7861/clinmedicine.6-6-536, indexed in Pubmed: 17228551

5. Broadbent E, Wilkes $\mathrm{C}$, Koschwanez $\mathrm{H}$, et al. The brief illness perception questionnaire. J Psychosom Res. 2006; 60(6): 631-637, doi: 10.1016/j.jpsychores.2005.10.020, indexed in Pubmed: 16731240.

6. Md Yusop NB, Yoke Mun C, Shariff ZM, et al. Factors associated with quality of life among hemodialysis patients in Malaysia. PLoS One. 2013; 8(12): e84152, doi: 10.1371/journal.pone.0084152, indexed in Pubmed: 24358336.

7. Aghakhani N, Sharif Nia H, Samad Zadeh S, et al. Quality of life during hemodialysis and study dialysis treatment in patients referred to teaching hospitals in Urmia-Iran in 2007. Caspian J Intern Med. 2011; 2(1) 183-188, indexed in Pubmed: 24024012.

8. Hedayati S, Bosworth H, Briley L, et al. Death or hospitalization of patients on chronic hemodialysis is associated with a physician-based diagnosis of depression. Kidney International. 2008; 74(7): 930-936 doi: 10.1038/ki.2008.311.

9. Abdel-Kader K, Unruh M, Weisbord S. Symptom Burden, Depression and Quality of Life in Chronic and End-Stage Kidney Disease. Clinical Journal of the American Society of Nephrology. 2009; 4(6): 1057-1064 doi: 10.2215/cjn.00430109

10. Carmichael P, Popoola J, John I, et al. Assessment of quality of life in a single centre dialysis population using the KDQOL-SF questionnaire. Qual Life Res. 2000; 9(2): 195-205, doi: 10.1023/a:1008933621829, indexed in Pubmed: 10983483.

11. Marc M, Saad MM, Douaihy YE, et al. et al.. Predictors of quality of life in patients with end-stage renal disease on hemodialysis Int J Nephro Renovasc Dis. 2015; 8: 119-123.

12. Kurella Tamura M, Covinsky KE, Chertow GM, et al. Functional status of elderly adults before and after initiation of dialysis. N Engl J Med. 2009; 361(16): 1539-1547, doi: 10.1056/NEJMoa0904655, indexed in Pubmed: 19828531.

13. O'Lone $\mathrm{E}$, Connors M, Masson P, et al. Cognition in People With End-Stage Kidney Disease Treated With Hemodialysis: A Systematic Review and Meta-analysis. Am J Kidney Dis. 2016; 67(6): 925-935, doi 10.1053/j.ajkd.2015.12.028, indexed in Pubmed: 26919914.

14. Stewart AL, Hays RD, Ware JE. Methods of validating MOS health Measures. In Measuring functioning and well-being: the medical outcomes study approach. Edited by:, Durham. NC: Duke University Press. : 1992: 309-324.
15. Saby A, Miller LS. Functional Assessment in End-Stage Renal Disease: Enhancing Quality of Life. Semin Dial. 2016; 29(2): 170-172, doi: 10.1111/sdi.12466, indexed in Pubmed: 26756940.

16. Leventhal $\mathrm{H}$, Brissette I, Leventhal EA. The common-sense model of self-regulation of health and illness In: Cameron LD, , editors. The self-regulation of health and illness behaviour. London. : Routledge.

17. Petrie KJ, Jago LA, Devcich DA. The role of illness perceptions in patients with medical conditions. Curr Opin Psychiatry. 2007; 20(2): 163-167, doi: 10.1097/YCO.0b013e328014a871, indexed in Pubmed: 17278916.

18. Vogel JJ, Godefroy WP, van der Mey AGL, et al. Illness perceptions, coping, and quality of life in vestibular schwannoma patients at diagnosis. Otol Neurotol. 2008; 29(6): 839-845, doi: 10.1097/MAO .0b013e3181820246, indexed in Pubmed: 18636026

19. Weisbord SD, Fried LF, Mor MK, et al. Renal provider recognition of symptoms in patients on maintenance hemodialysis. Clin J Am Soc Nephrol. 2007; 2(5): 960-967, doi: 10.2215/CJN.00990207, indexed in Pubmed: 17702730.

20. Boini S, Frimat L, Kessler M, et al. Predialysis therapeutic care and health-related quality of life at dialysis onset (The pharmacoepidemiologic AVENIR study). Health Qual Life Outcomes. 2011; 9: 7, doi: 10.1186/1477-7525-9-7, indexed in Pubmed: 21261936.

21. Palmer BF, Clegg DJ, Palmer BF, et al. Sexual dysfunction in men and women with chronic kidney disease and end-stage kidney disease. Adv Ren Replace Ther. 2003; 10(1): 48-60, doi: 10.1053/jarr.2003.50003, indexed in Pubmed: 12616463

22. Kim Y, Evangelista LS, Phillips LR et al. The End-Stage Renal Disease Adherence Questionnaire (ESRD-AQ): testing the psychometric properties in patients receiving in-center hemodialysis. Nephrol Nurs J. 2010; 37(4): 377-393, indexed in Pubmed: 20830945

23. Fowler C, Baas LS. Illness representations in patients with chronic kidney disease on maintenance hemodialysis. Nephrol Nurs J. 2006; 33(2): 173-4, 179, indexed in Pubmed: 16613412.

24. Cohen SD, Cukor D, Kimmel PL. Anxiety in Patients Treated with Hemodialysis. Clin J Am Soc Nephrol. 2016; 11(12): 2250-2255, doi: 10.2215/CJN.02590316, indexed in Pubmed: 27660303.

25. Gonzalez K, Ulloa JG, Moreno G et al. Intensive procedure preferences at the end of life (EOL) in older Latino adults with end stage renal disease (ESRD) on dialysis. BMC Nephrol. 2017; 18(1): 319, doi: 10.1186/s12882-017-0739-7, indexed in Pubmed: 29061178.

26. M. Sue McManus. Illness representation and medication adherence of patients with chronic kidney disease. Faculty of Indiana University, 2011. . https://scholarworks.iupui.edu/bitstream/handle/1805/2751/dissdftsubmitscholarworks? sequence $=1$

27. Boudreau JE, Dubé A. Quality of life in end stage renal disease: a concept analysis. CANNT J. 2014; 24(1): 12-20, indexed in Pubmed: 24783768

28. Gentile S, Jouve E, Dussol B, et al. Development and validation of a French patient-based health-related quality of life instrument in kidney transplant: the ReTransQoL. Health Qual Life Outcomes. 2008; 6: 78, doi: 10.1186/1477-7525-6-78, indexed in Pubmed: 18851730

29. Gentile S. [Principal determinants of quality of life]. Soins. 2004(688 Suppl): 4, indexed in Pubmed: 15526819.

30. von der Lippe N, Waldum B, Brekke FB, et al. From dialysis to transplantation: a 5-year longitudinal study on self-reported quality of life. BMC Nephrol. 2014; 15: 191, doi: 10.1186/1471-2369-15-191, indexed in Pubmed: 25465066

31. Kusztal M, Nowak K, Magott-Procelewska M, et al. [Evaluation of health-related quality of life in dialysis patients. Personal experience using questionnaire SF-36]. Pol Merkur Lekarski. 2003; 14(80): 113-117. indexed in Pubmed: 12728668.

32. Bapat U, Kedlya PG. Gokulnath. Perceived illness intrusions among continuous ambulatory peritoneal dialysis patients. Saudi J Kidney Dis Transpl. 2012; 23(5): 958-964, doi: 10.4103/1319-2442.100876, indexed in Pubmed: 22982907.

33. Jaar BG, Chang A Plantinga L Can we improve quality of life of patients on dialysis? Clin J Am Soc Nephrol. 2013; 8(1): 1-4, doi: 10.2215/CJN.11861112, indexed in Pubmed: 23296376.

34. Pagels AA, Söderkvist BK, Medin C, et al. Health-related quality of life in different stages of chronic kidney disease and at initiation of dialysis treatment. Health Qual Life Outcomes. 2012; 10: 71, doi: 10.1186/14777525-10-71, indexed in Pubmed: 22710013

35. Feroze U, Noori N, Kovesdy C, et al. Quality-of-Life and Mortality in Hemodialysis Patients: Roles of Race and Nutritional Status. Clinical Journal of the American Society of Nephrology. 2011; 6(5): 1100-1111, doi: 10.2215/cjn.07690910. 